\title{
Kekerasan Baja Karbon Sedang dengan Variasi Suhu Permukaan Material
}

\author{
Dwipayana $^{1)^{\star}}$, ( Made Widiyarta ${ }^{2)}$, Made Sucipta ${ }^{2)}$ \\ ${ }^{1)}$ Program Studi Magister Teknik Mesin, Fakultas Teknik, Universitas Udayana \\ Kampus Sudirman, Bali 80232 \\ Email: dwipayana cool@yahoo.com \\ 2) Jurusan Teknik Mesin, Fakultas Teknik, Universitas Udayana \\ Kampus Bukit Jimbaran, Bali 80362 \\ Email: m.widiyarta@unud.ac.id, m.sucipta@gmail.com
}

doi: https://doi.org/10.24843/METTEK.2018.v04.i02.p02

\begin{abstract}
Abstrak
Beban gesek pada permukaan sebuah benda dapat menimbulkan panas pada permukaan kontak benda tersebut. Semakin besar beban gesek yang terjadi, suhu pada permukaan material akan menjadi lebih tinggi. Peningkatan suhu permukaan yang semakin tinggi dapat mempengaruhi sifat mekanis permukaan material dan tentunya dapat berimplikasi terhadap mekanisme kegagalan pada permukaan material tersebut, seperti kegagalan aus dan kegagalan retak. Pada penelitian ini, uji kekerasan dilakukan pada material dengan suhu permukaan tertentu. Permukaan material baja karbon sedang dipanaskan dengan variasi suhu yaitu mulai dari suhu kamar sampai dengan $300^{\circ} \mathrm{C}$, kemudian dilakukan uji Vicker's. Tingkat kekerasan dan profil indentasi Vickers pada permukaan material dengan variasi suhu tersebut kemudian diinvestigasi.
\end{abstract}

Kata kunci: beban gesek, suhu permukaan, baja karbon, kekerasan.

\section{Abstract}

Friction load on the surface of an object can cause heat on the contact surface of the object. The larger the frictional load occurs, the temperature on the surface of the material will become higher. Increased surface temperatures can further affect the mechanical properties of the material surface and can certainly have implications for the failure mechanisms on the surface of the material, such as wear failure and crack failure. In this study, hardness tests were performed on materials with certain surface temperature. The surface of the carbon steel material is being heated with temperature variations ranging from room temperature up to $300^{\circ} \mathrm{C}$, then Vicker's test. The degree of hardness and Vickers indent profile on the surface of the material with the temperature variation is then investigated.

Keywords: frictional load, surface temperature, carbon steel, hardness.

\section{PENDAHULUAN}

Aus merupakan kegagalan permukaan komponen yang dapat mempengaruhi kinerja komponen karena perubahan profil permukaan. Aus terjadi karena terlepasnya partikel dari permukaan material suatu komponen. Kegagalan aus dipengaruhi oleh sifat mekanik material, beban kerja komponen dan kondisi permukaan kontak, salah satunya yaitu munculnya panas (meningkatnya suhu permukaan kontak) akibat gesekan [1]. Sebagai contoh kontak antara roda dan rel kereta api akan menghasilkan tekanan dan gesekan sehingga dapat menyebabkan pengikisan permukaan komponen. Menurut penelitian Evtushenko [2], peningkatan energi termal yang terbentuk dari gesekan antara roda dan rel kereta api akan diubah menjadi panas

Penulis korespondensi

Email: dwipayanacool@yahoo.com 
pada permukaan kontak keduanya. Bila suhu permukaan tersebut cukup tinggi dan merubah sifat mekanis material, maka akan mempengaruhi mekanisme aus dan mempercepat laju keausan material, sehingga memperpendek umur pemakaian komponen.

Meningkatnya suhu permukaan kontak antar dua material yang bergesekan, dapat menyebabkan kekerasan material semakin menurun dan laju keausan semakin tinggi. Uji kekerasan perlu dilakukan untuk memahami laju keausan permukaan material akibat timbulnya panas saat gesekan. Pada penelitian ini, uji kekerasan dilakukan pada material dengan suhu permukaan tertentu. Permukaan material baja karbon sedang dipanaskan dengan variasi suhu yaitu mulai dari suhu kamar sampai dengan $300^{\circ} \mathrm{C}$, kemudian dilakukan uji Vicker's.

\section{METODE}

\subsection{Baja Karbon}

Baja merupakan suatu besi yang mengandung kadar karbon berkisar sekitar 1,7\%. Material ini secara teknik disebut sebagai baja karbon [3]. Pembuatan baja dilakukan melalui proses Bassemer, Thomas, Siemens Martin dan metode penghembusan oksigen. Baja dapat dibentuk melalui pengecoran, pencanaian, dan penempaan. Baja karbon mempunyai sifat yang ditentukan oleh banyaknya kadar karbon yang ada dalam baja dan struktur mikro baja. Secara umum baja karbon digolongkan menjadi tiga jenis antara lain:

1. Baja karbon rendah, memiliki kandungan karbon sebesar $0,10 \%-0,30 \%$.

2. Baja karbon sedang, memiliki kandungan karbon sebesar $0,31 \%-0,60 \%$.

3. Baja karbon tinggi, memiliki kandungan karbon $0,61 \%-1,5 \%$.

\subsection{Kekerasan}

Kekerasan merupakan ketahanan material terhadap suatu deformasi yang terjadi di daerah lokal. Bila materialnya berupa logam maka deformasi yang dimaksud yaitu deformasi plastis. Semakin keras suatu material maka material tersebut semakin kuat. Kekerasan material berbanding lurus terhadap kegetasannya dan berbanding terbalik dengan keuletannya.

Penelitian ini menggunakan metode pengujian Vickers yang memiliki beberapa kelebihan. Selain material lunak, pengujian Vickers dapat dilakukan pada material yang keras. Kerusakan bahan percobaan pada pengujian Vickers relatif sedikit dan kekerasan dapat diukur dengan gaya yang relatif kecil pada permukaan spesimen yang tipis.
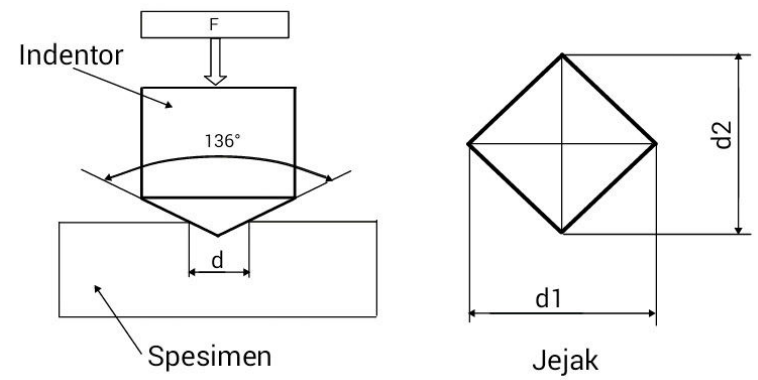

Gambar 2. 1. Skematik uji Vickers dan pengukuran dimensi bekas indentasi paramida [4]

Angka kekerasan Vickers (HVN) merupakan angka kekuatan benda uji terhadap pembebanan pada tiap luas penampang bidang yang menerima pembebanan [5]. HVN dapat diperoleh dengan persamaan berikut: 


$$
H V N=\frac{2 P \sin \frac{\theta}{2}}{d^{2}}=\frac{(1,854) P}{d^{2}}
$$

dimana:

$\mathrm{P} \quad=$ beban yang digunakan $(\mathrm{kg})$;

$\Theta=$ sudut puncak indentor $=136^{\circ}$ dan,

$\mathrm{d} \quad=$ panjang diagonal rata-rata $(\mathrm{mm})$.

\section{HASIL DAN PEMBAHASAN}

\subsection{Pengujian Kekerasan}

Pengujian kekerasan dilakukan menggunakan metode pengujian kekerasan Vickers sesuai standar ASTM E384. Angka kekerasan Vickers didapat dari beban dibagi oleh luas permukaan lekukan yang dihitung menggunakan pengukuran mikroskopik panjang diagonal jejak.

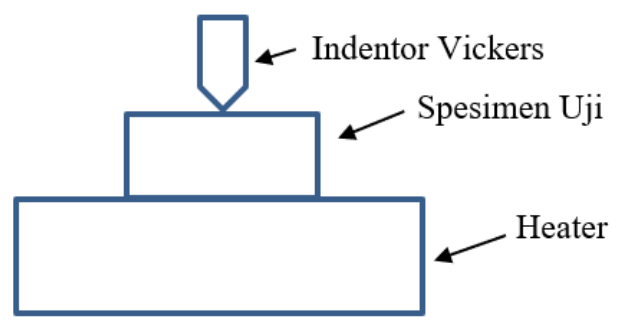

Gambar 3.1. Skema uji kekerasan

Langkah-langkah pengujian kekerasan Vickers adalah sebagai berikut:

1. Persiapkan spesimen sesuai standar:

a. Ratakan permukaan spesimen menggunakan gerinda dan amplas grid 80, 240 dan 600.

b. Permukaan spesimen dihaluskan menggunakan amplas grid 1000 dan 2000 serta kain beludru dengan pasta autosol.

2. Perangkat uji kekerasan Vickers dipersiapkan dengan baik:

a. Pasang beban sebesar 1000 gram.

b. Pasang indentor piramida intan yang bersudut $136^{\circ}$ pada alat uji.

c. Pasang spesimen dan heater pada perangkat uji.

d. Atur handel dengan posisi atas.

3. Posisikan ujung indentor pada permukaan benda kerja.

4. Nyalakan heater dan tunggu hingga suhu permukaan spesimen mencapai suhu yang diinginkan.

5. Lepaskan handel secara perlahan tanpa tekanan ke bawah, handel akan bergerak turun dengan sendirinya. Biarkan jarum besar pada skala turun sampai berhenti.

6. Saat jarum mulai berhenti, tunggu selama 10 detik sebelum menggerakkan handel ke atas menjauhi permukaan spesimen.

7. Ulangi pengujian dengan menggeser spindel ke arah samping spesimen pada jarak 1 mm sebanyak 3 kali.

8. Setelah selesai, matikan heater dan lepaskan spesimen dari landasan serta foto setiap titik pengujian kekerasan pada mikroskop metalurgi dengan pembesaran 500.

9. Setelah hasil foto didapatkan, buka foto pada image dan ukur diagonal masingmasing titik indentasi dengan menggunakan skala yang ada pada mikroskop.

10. Penghitungan kekerasan menggunakan persamaan 2.1 di tiap titik indentasi. 


\subsection{Hasil Pengujian Kekerasan}

11. Ulangi semua langkah di atas pada semua spesimen.

Material yang dipilih merupakan pendekatan dari material yang biasa dipakai sebagai bahan pembuatan komponen permesinan. Baja karbon sedang yang digunakan adalah baja karbon komersial ST70 yang merupakan baja karbon sedang dengan kandungan karbon 0,5\% [6].

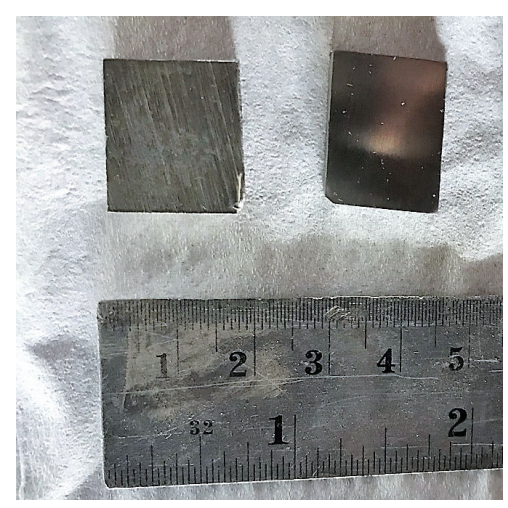

Gambar 3.2. Preparasi spesimen baja karbon sedang ST70

Gambar 3.2 menunjukkan preparasi spesimen baja karbon sedang ST70 untuk uji kekerasan. Spesimen dibentuk dengan ukuran $20 \mathrm{~mm}$ x $15 \mathrm{~mm}$ x $8 \mathrm{~mm}$. Spesimen sebelah kiri atas merupakan spesimen hasil pemotongan awal menggunakan mesin pemotong. Spesimen sebelah kanan atas merupakan spesimen yang telah dihaluskan permukaannya menggunakan gerinda dan amplas grid 80, 240, 1000, 2000 serta kain beludru dengan pasta autosol.

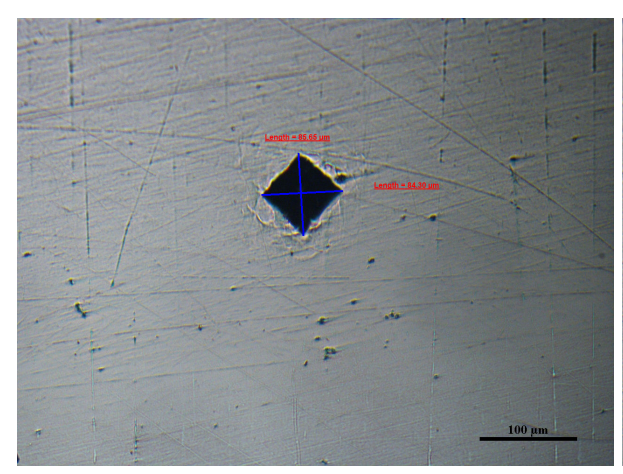

a

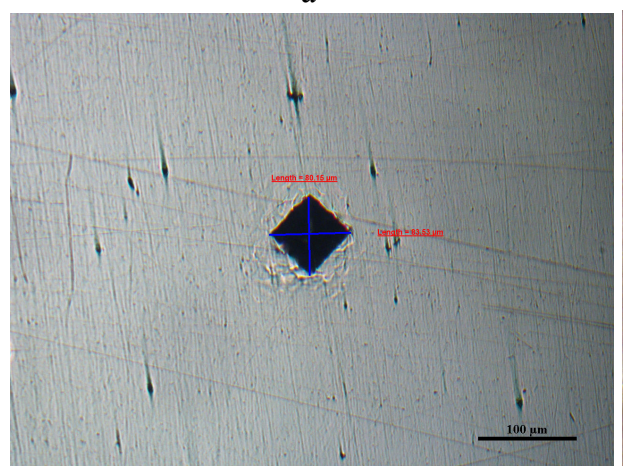

c

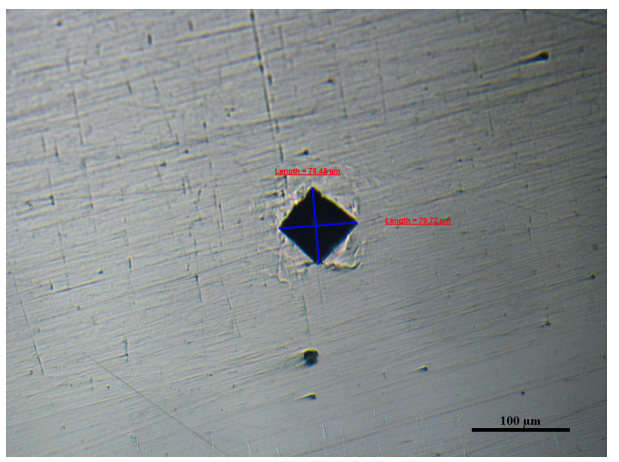

b

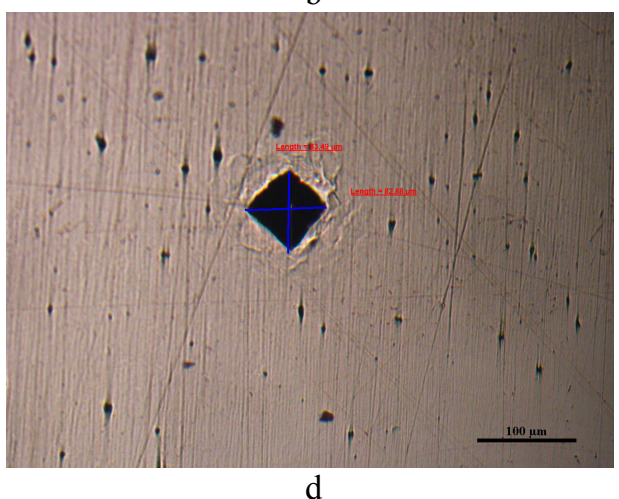




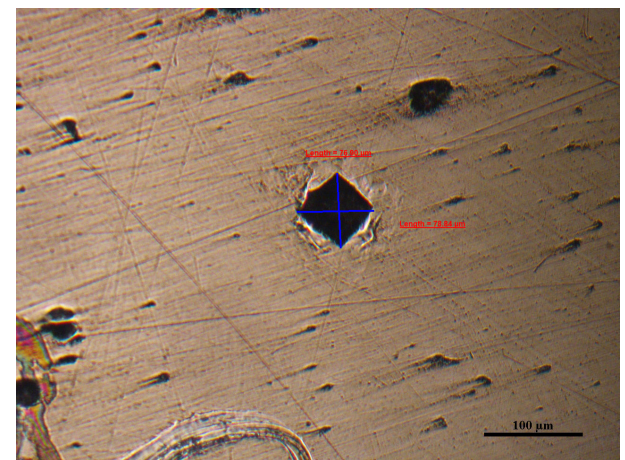

e

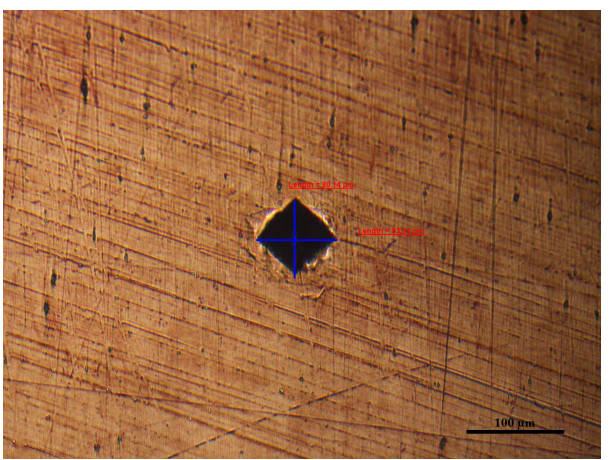

f

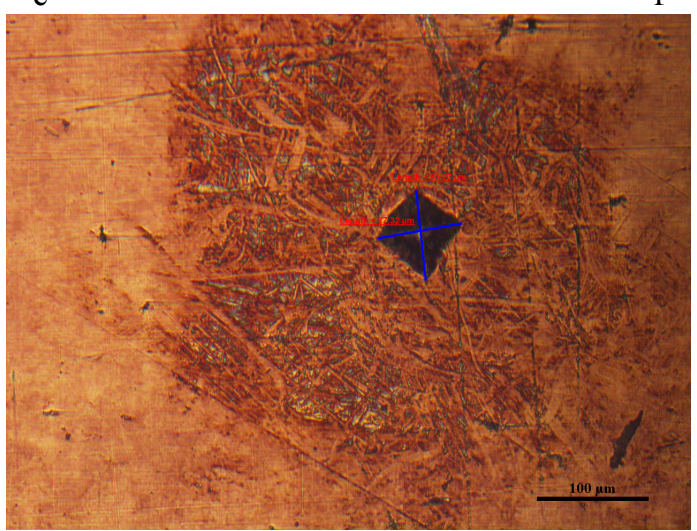

g

Gambar 3.3. Indentasi baja karbon sedang ST70 bagian atas pada berbagai suhu a) $30^{\circ} \mathrm{C}$, b) $50^{\circ} \mathrm{C}$, c) $100^{\circ} \mathrm{C}$, d) $150^{\circ} \mathrm{C}$, e) $200^{\circ} \mathrm{C}$, f) $250^{\circ} \mathrm{C}$, g) $300^{\circ} \mathrm{C}$

Gambar 3.3 menunjukkan indentasi karbon baja sedang ST70 pada rentang suhu $30^{\circ} \mathrm{C}$ sampai $300^{\circ} \mathrm{C}$. Ada perbedaan warna lapisan permukaan pada rentang suhu $150^{\circ} \mathrm{C}$ sampai $300^{\circ} \mathrm{C}$ yang kemungkinan merupakan warna dari lapisan oksida pada permukaan spesimen. Berdasarkan jejak indentasi dapat diamati bahwa material baja karbon sedang ST70 tidak mengalami deformasi pada rentang suhu permukaan $30^{\circ} \mathrm{C}$ sampai $300^{\circ} \mathrm{C}$.

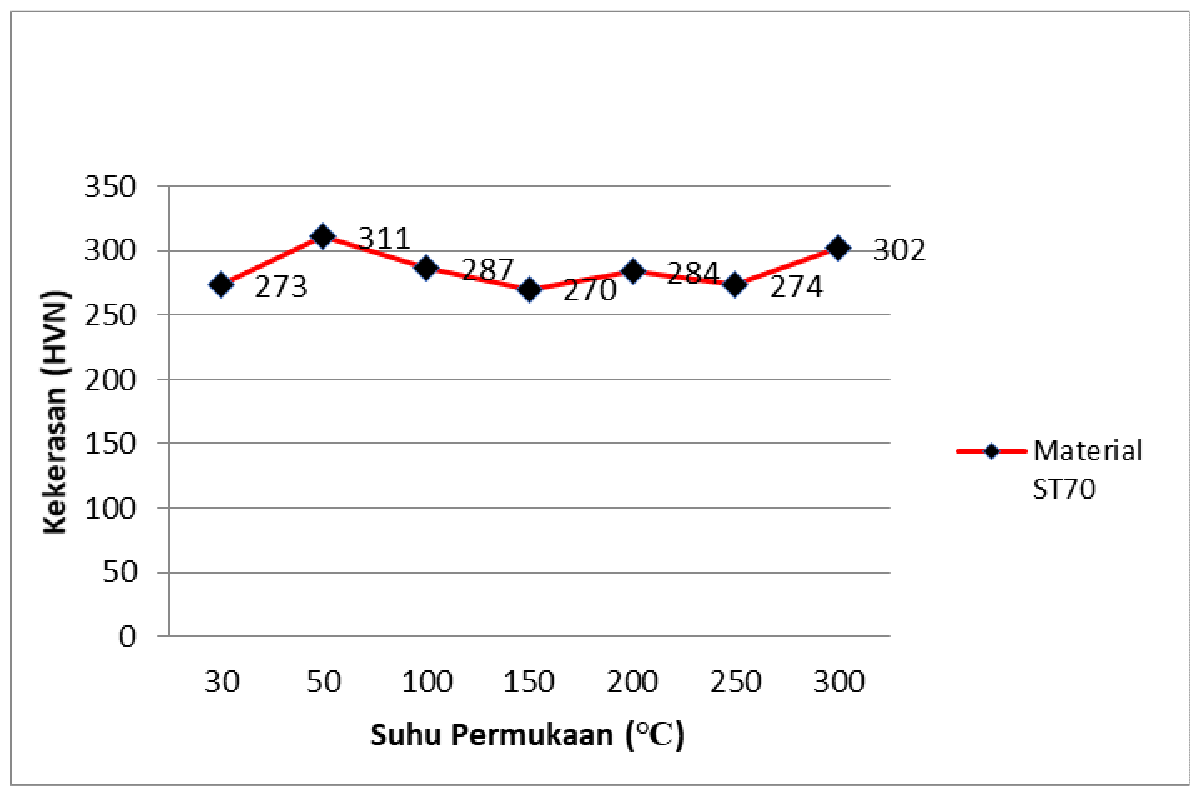

Gambar 3.4. Kurva uji kekerasan baja karbon sedang ST70 
Gambar 3.4 menunjukkan nilai kekerasan baja karbon sedang ST70 pada rentang suhu $30^{\circ} \mathrm{C}$ sampai $300^{\circ} \mathrm{C}$. Pada suhu $30^{\circ} \mathrm{C}$, baja karbon sedang ST70 memiliki nilai kekerasan 273 HVN. Pada suhu $50^{\circ} \mathrm{C}$, nilai kekerasan meningkat menjadi $311 \mathrm{HVN}$. Pada suhu $100^{\circ} \mathrm{C}$, nilai kekerasan turun menjadi $287 \mathrm{HVN}$. Pada suhu $150^{\circ} \mathrm{C}$, nilai kekerasan semakin menurun yaitu 270 HVN. Pada suhu $200^{\circ} \mathrm{C}$, nilai kekerasan sedikit meningkat menjadi $284 \mathrm{HVN}$, namun nilai ini masih lebih kecil dari nilai kekerasan pada saat suhu $50^{\circ} \mathrm{C}$. Pada suhu $250^{\circ} \mathrm{C}$, nilai turun lagi menjadi $274 \mathrm{HVN}$. Pada suhu $300^{\circ} \mathrm{C}$, nilai kekerasan meningkat menjadi $302 \mathrm{HVN}$. Kemungkinan pada suhu $300^{\circ} \mathrm{C}$ sudah terbentuk lapisan oksida pada spesimen baja karbon sedang ST70 yang menyebabkan kekerasan semakin meningkat.

\section{SIMPULAN}

Berdasarkan hasil uji Vickers, dapat disimpulkan yaitu:

1. Material baja karbon sedang dapat mengalami perubahan sifat mekanis pada saat perubahan suhu dari $30^{\circ} \mathrm{C}$ sampai $300^{\circ} \mathrm{C}$ yaitu semakin meningkatnya suhu permukaan, kekerasan menjadi semakin rendah.

2. Pada suhu $300^{\circ} \mathrm{C}$, baja karbon sedang mengalami perubahan sifat mekanis yaitu kekerasan menjadi semakin tinggi, kemungkinan akibat dari pengaruh lapisan oksida di permukaan material.

\section{UCAPAN TERIMA KASIH}

Kami memanjatkan puji syukur kepada Tuhan Yang Maha Kuasa karena berkat anugerah Nya penelitian ini bisa terselesaikan. Terima kasih kami ucapkan juga kepada:

1. Balai Teknologi Industri Kreatif Keramik, Badan Pengkajian dan Penerapan Teknologi atas dukungannya pada penelitian ini.

2. Universitas Udayana yang telah membantu sebagai penyelenggara KNEP IX 2018 dan penyedia Laboratorium Produksi dan Laboratorium Metalurgi.

3. Seluruh sahabat yang telah membantu melalui semangat dan doa sehingga penelitian bisa terlaksana dengan baik.

\section{DAFTAR PUSTAKA}

[1] Hasry, Muhammad, Kaelani, Yusuf. 2014. Studi eksperimental keausan permukaan material akibat adanya multi-directional contact friction. Jurnal Teknik Pomits. Vol. 1 No. 1, Hal. 1-6.

[2] Evtushenko, O.O. et al. 2002. Investigation of the temperature field induced in the process of friction a wheel against a rail. Material Science. Vol. 38 Issue 5, Hal. 709716.

[3] Jensen dan Chenoweth. 1992. Kekuatan Bahan Terapan. Jakarta : Erlangga.

[4] ASTM E384. 2012. Standard Test Method for Knoop and Vickers Hardness of Material.

[5] Koswara, Engkos. 1999. Pengujian Bahan Logam. Bandung : Humaniora Utama Press.

[6] Sardjono, KP. K. 2009. Pengaruh hardening pada baja JIS G 4051 Grade S45C terhadap sifat mekanis dan struktur mikro. Jurnal Sains dan Teknologi Indonesia, Vol. 11 No. 2, Hal. 95-100. 